\title{
Enlightenment of Nobel Prize to Chinese University Teaching \& Research Management
}

\author{
Pei Shixin \\ School of Physics \& Optoelectronic Engineering \\ Nanjing University of Information Science \& Technology, \\ NUIST \\ Nanjing, China, 210044 \\ Peishixin@nuist.edu.cn \\ Cui Fenping \\ School of Physics \& Optoelectronic Engineering \\ Nanjing University of Information Science \& Technology, \\ NUIST \\ Nanjing, China, 210044
}

\begin{abstract}
Statistical analysis number of prize presentation, number of prize winners, number of achievement awards, per capita amount of achievements as well as the winners' ages and nationalities who were awarded Nobel Prize in chemistry, physics, physiology \& medicine, as well as the total number of the three kinds of awards in the period of 1901-2013. The causes of changes of Nobel natural science prize winners' nationality, age and per capita amount of achievements are analyzed. According to the reasons of the changes, it is concluded that to strengthen the scientific research investment, create advantages of scientific research platform, make reasonable personnel policy, attract and pool talent, emphasis on the development of young and middle-aged teachers, continues to expand and deepen international,exchanges,enhanceteachers'internationalizatio $n$ level and ability to improve the quality of the teaching and scientific and promote the development of colleges and universities.
\end{abstract}

Keywords-Management; Nobel Prize; Higher Education; University; Internationalization

\section{INTRODUCTION}

Nobel Prize is the award established in accordance with the Swedish chemist Nobel's will. It was established to honor scientists who made outstanding contributions in physics, chemistry, physiology \& medicine, literature and peace [1]. Except Noble peace and literature prize, the other three awards are all about natural science, so they can be called as Nobel Science Prize. They are the most important scientific award. The achievements largely represent the highest level of scientific research and development trend of mankind. It plays a huge effect in the promotion of human research, technological progress and social development. Usually, the amount of Nobel prizes is often used to evaluate the success of a national science policy and position in the scientific community [2].

Based on the importance of the Nobel Prize, many countries have started to research the Nobel Prize, and a new discipline, Nobel Learning has formed [3]. The angles of Nobel Learning study are different, such as the

\author{
Luo Yuanmei \\ School of Physics \& Optoelectronic Engineering \\ Nanjing University of Information Science \& Technology, \\ NUIST \\ Nanjing, China, 210044
}

angle of sociology [4], management science [5, 6], pedagogic [7, 8], and science history [9], etc.

In this paper, Nobel Natural Science Prize (prize in chemistry, physics, physiology \& medicine) winners are used as statistics object, a 10 years is used as a period time, from 1901 to 2013 , the winners nationality distributions, award-winning ages and the amount of achievements during each time was statistics. The winners' regular distribution features are found and it will be helpful for the teaching and management of higher education of China.

\section{NOBEL SCIENCE PRIZE OVERVIEW}

The Nobel Prize has covered 113 years from 1901 when the Nobel Prize in physics, chemistry, physiology or medicine was issued for the first time to 2013. And it was hold annually except suspended for the first and second world war and the depression.

Until the 2013 Nobel Prize, the Nobel Prize for physics was hold 107 times totally, 196 physicists won the prize; The Nobel Prize for chemistry was hold 105 times, 166 chemists were awarded; And the Nobel Prize in physiology or medicine (short for the Medical award below) was hold 104 times, 204 scientists were awarded.

In the 113 years' history of Nobel Science Prize, there are a total of 566 Award Winners. One of whom, named Marie Curie, from France. She obtained the Nobel Prize in physics and chemistry in 1903 and 1911 respectively. She was the only person who won Nobel Prize both of physics and chemistry scientists and also is one of the few female scientists. The American physicist John Bardeen won the Nobel Prize in Physics two times in 1956and in 1972. Frederick Sanger, an English biochemist won the Nobel Prize twice in Chemistry in 1958 and in 1980 . By the end of 2013, 563 people have won the prize around the world, except the above three person who won the Nobel Prize twice in the world. 


\section{DISTRIBUTION AND ENLIGHTENMENT OF WINNERS NATIONALITY}

\section{A. The winners nationality distribution in 1901-2013}

According to information on the official website of the Nobel Prize [1], in a 10-year interval since 1901, winners of physics, chemistry, physiology \& medicine is statistics by nationality, for the winners have dual citizenship is statistical 0.5 times for both countries, the winners of the former Soviet Union is statistics in Russia.

The statistic results showed that until 2013 Nobel Prize announced, Chemistry laureate were 166, distributed in 24 countries, the top eight countries are USA, Germany, Britain, France, Japan, Switzerland, Israel, Sweden and Netherlands, 62.5 winners have United States nationality; Physics laureate were 196 people, distributed in 19 countries, the top eight countries are USA, Germany, Britain, France, Russia, Netherlands, Japan and Sweden, and 89 winners have United States nationality; Physiology \& Medicine laureate were 204 people, distributed in 21 countries, the top eight countries are USA, Britain, Germany, France, Sweden, Australia, Switzerland and Denmark, 95.5 winners have United States nationality.

Summarizing Nobel Prize of chemistry, physics and physiology \& medicine, the total Noble prize winners were 566, distributed in 30 countries, if the winners are sorted by the nationality, the top eight countries are USA, Britain, Germany, France, Switzerland, Sweden, Japan and the Netherlands, among the winners, 247 winners have United States nationality. Japanese scientist Yuasa Hikaru believed when one country's scientific achievements is $25 \%$ of the total number of world major scientific results over the same period, the country is known as the world science center [10], according to Yuasa Hikaru definition, the United States is the world worthy of the world's scientific activity center.

The statistical results show that in the individual winner of the 8 top countries, the countries which the three kinds of Nobel Prize winners of physics, chemistry and physiology \& medicine distributed are USA, Britain, Germany and France, the winners were147, 124.5, 152 and 423.5, respectively, the percentage of the total number of each subject awards were 75, 75, 74.51 and 74.82, therefore, the change of Nobel Natural Science Price winners distribution in America, Britain, Germany and France represent the change of the world scientific activities centre in great extent.

\section{B. Distribution of USA, three countries (Britain, France \& Germany) and the other twenty-six countries}

According to the statistical results, chronologically, based on the winners' nationalities, in every 10-year period from 1901 to 2013, the distribution of the noble prize winners of physics, chemistry, physiology \& medicine are shown in Fig. 1.

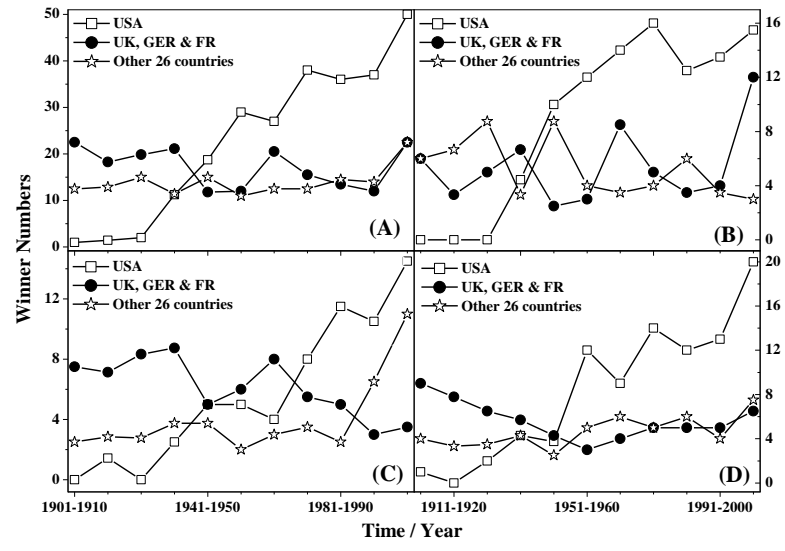

Figure 1. Breakdown by nationality of 1901-2013 winner of the Nobel Prize in Science

In fig. 1, the nationality of the winner of a U.S. citizen classified as a class, marked as USA; The winners for the UK, GER and FR is normalized as a class, marked as UK, GER \& FR; Except USA, UK, GER and FR, the winners of the other 26 countries is classified as a class, and marked as other 26 countries in fig. 1, where Fig. 1(A) shows certain nationalities won three awards in the total number of changes over time, Fig. 1(B), 1(C), 1(D), respectively, show certain nationalities obtained raw Prize in Medicine, trips Prize in Chemistry and Physics Prize change over time.

Under the influence of world economic depression and the two world wars, the Nobel Prize is subject to different degrees. As 1911-1920 years, did not award prize in physics in 1916, 1916,1917 and 1919 chemistry prize in three years is not the awards, the Health Prize for Medicine in 1915-1918 did not award four years, the situation in 1921-1930, $1931-1940$ and 1941-1950 have occurred.To this result does not affect the citizenship award winners of the distribution curve caused to reduce as much as possible when plotted against the raw statistics do the following correction: In the affected time period, the time period of the award-winning trips divided by the number of annual awards, and then multiply by 10 the number of awards as the time period of certain nationalities obtained, then the processed data to make plot.

It is shown in Fig. 1, the Nobel Prize in PHYS., CHEM., P\&M winning three awards and the total number is consistent with the distribution of the time, their common characteristic is in the early awards, with Britain, Germany, France Nobel laureate majority membership, Before the 1940s, has maintained a majority position, indicating that before the Second World War, the world center of scientific activity in Europe, but with time, with a Nobel Prize winner visits overall Britain, Germany, France and nationality declining, From the mid-1930s, Nobel laureate people have U.S. citizenship is rising, and in the 1940s for the sector, the future Nobel Prize winner in each time period has U.S. citizenship award trips have begun to surpass Britain, Germany, visitors and nationality law. 


\section{Causes of winners, nationality distribution and Its Implications for university management}

As it is shown in Fig. 1, there is a turning point in World War II time, this point means the predominance of Nobel Natural Science Prize changed from Europe to America, and after World War II, noble prize winners of American is majority, and the ratio is increasing, this conversion of the Nobel laureate nationality distribution illustrated that the world center of scientific activity from Europe to the United States.

The change of the world science center from Europe to the United States illustrated that to attract and gather talents is the core of science and technology, and it can be said that the transfer of the science center, in the final analysis, it is the transfer of talent center, it is the transfer of the research requirement, and it is also the transfer of the economic center of the world, while the outbreak of two world wars in the 20th century created the condition of this transfer.

It is well known, the two technological revolution which at the end of 18th century and early 19th century and 1870s have originated in Europe, both of the two technological revolution laid the foundation for Europe to become the world scientific activity center in 19th century, but in the 20th century, as the main battlefield of the two world wars are originated from Europe, and engulfed the Eurasian continent, especially at the Second World War, the role of great destructive power of modern warfare lead to the European economy was hit. Moreover, in the 1920s, Europe was set off against the Jews currents, resulting in the loss of a number of Jewish scientists, and although the United States was involved in World War II, eventually, but the war did not burn to the United States, so during World War II, the United States has not been harassment of local wars, becoming the only industrialized country without a war-torn, to carry out scientific research to provide a more stable environment to attract talented people into the United States to create the conditions, the U.S. government also fully seize this favorable conditions to provide good conditions for scientific research, a large number of European scientists were intruded into the United States, which greatly promoted the development of science and technology in the United States. And because of World War II not spread to the United States, the U.S. economy is influenced by World War II is relatively small, which makes the postwar U.S. economy has been in a leading position in the world economy, which create the necessary economic conditions for scientific research.

The transfer of world science activities center show that economic base, talents, research environment play a important role in the development of science, therefore, which developing a reasonable personnel policy, creating a platform for high-level research, gathering talented technologists, and excavating potential talent is the only way of collages and universities to improve the quality of teaching and research.

\section{WINNERS AGE DISTRIBUTION AND ENLIGHTENMENT}

\section{A. Noble Prize winners ages distribution}

For comparison, according to the statistical results, based on age distribution from 1901 to 2013, the Nobel
Prize winners in physics, chemistry, physiology \& medicine and three awards in total are shown in fig. 2, Fig. 2(A), 2(B), 2(C) and 2(D) show the Nobel Prize winners in chemistry, physics, physiology \& medicine and total winners age distribution.

As it is shown in Fig. 2, the overall age of the Nobel Prize in physics, chemistry, physiology \& medicine are normally distributed. Where fig. 2(A) shows the age distribution of Nobel Prize winner is a standard normal distribution curve, where the top five winners' ages were 56-60, 51-55, 61-65, 46-50 and 66-70. The Nobel laureate of chemistry. In the distribution of the four ages awardwinning accumulated to 115 , accounting for $69.28 \%$ of the total award.

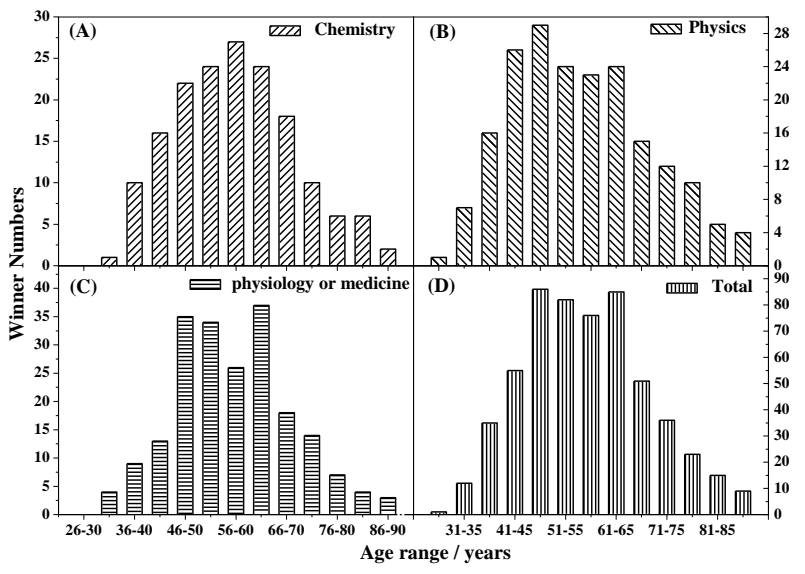

Figure 2. 1901-2013 Nobel Prize winners age distribution

From Fig. 2(B) can be seen, the age distribution of Nobel Laureate in Physics to chemistry are relatively scattered, but also showed a normal distribution, which the top five winners were ages 46-50, 41-45, 51-55, 61-65 and $56-60$, the Nobel Laureate in physics winners in the distribution of the total winners, ages to 126 , accounting for $64.28 \%$ of the total award.

As it is shown in Fig. 2(C), for the laureate of physiology \& medicine, there is an abnormal distribution in 61-65 age group, other age groups are showing good normal distribution, which the top five winners ages are 61-65, 46-50, 51-55, 56-60, the Nobel Prize Laureate in physiology \& medicine. Distributed in the total number of award-winning five ages of 150 , accounting for $73.53 \%$ of the total award.

As it is shown in Fig. 2(D), physiology \& medicine Prize winner affected by age distribution, winner of three awards in addition to the age distribution of the sum of the ages of 61-65 is slightly abnormal addition, the winner was the distribution of other ages standard normal distribution, which trips the top five winners were 46-50, 61-65, 51-55, 56-60 and 41-45, the Nobel Prize winner in the distribution of natural science in the total number of award-winning five age is 384 , accounting for $67.84 \%$ of the total winner of the Nobel Prize in Science trips.

\section{B. Causes of winners age distribution and Its Implications for Chinese university management}

As the histogram graph shown in fig. 2, the age of the winners is mainly in 46-65 years old, this corresponds to the physiological age of the main maturity and aging period but that does not mean get creative research Nobel 
laureate age is at this stage, the age when they win the prize is deferred compare with the age when they achievements in scientific research.

Although the Nobel Prize history, there have been like Yang, Lee made a creative research in the first year (1956), the second year (1957) was confirmed and received the Nobel Prize in Physics which is especial, but in general, because research requires repeated testing, a new discovery or theory has been widely recognized in the scientific community needs to go through a difficult process, but an important research results from a proposal to get the Nobel Prize years needed a lots years, or even decades. Such as the American chemist Roger Tsien research results published 15 years won the Nobel Prize in Chemistry in 2008, and from 1966 Kao proposed optical fiber communication theory to get the Nobel Prize in Physics in 2009, has experienced 43 years. Two scientists who get the Noble Prize which because "God particle", it is experienced half a century that form they put forward theory to award prize. According to statistics, a physicist from recognized to contribute to the average need to wait a full 18 years.

According to the statistical results, the main age of the Nobel Prize winners focused on 46-65, taking into account the average time from the research presented to award, it can be drawn that a winner's achievements age is generally 28-47; it means that youth is the backbone of innovation achieved. According to general international educational system, 28-year-old is generally the Ph.D. age, which means that the starting point of research is the doctorate, but for a doctorate, his mentor's role can not be ignored.

It shows from the above analysis of Noble Prize winners' age distribution, in the process of teaching and research, university must pay attention to the training of young teachers and veteran teachers in the role play situation, however, in our universities, the young teachers facing the dual pressure of work and life. Therefore, in order to give full play to the ability of young teachers, universities should try to create the conditions for the young teachers to maximize ease the pressure on their life and work establishing a scientific evaluation system, creating good conditions for scientific research, and providing a relaxed research atmosphere to encourage young teachers to carry out research work and involved in research. Attract talent from the emotional, policies, retain talent from the research environment, living conditions and attract more talented people to the teaching and research.

\section{IMPLICATIONS OF PRIZE PRESENTATION TIMES AND WINNERS NUMBER AND PER CAPITA ACHIEVEMENT}

\section{A. Nobel Prize award times and winners number}

Ten years is still as a statistical time period, and in every period, the noble prize presentation times, number of chemistry, physics and physiology \& medicine prize winners and achievement award are counted in 1901-2013, the results are shown in Table 1.

It can be found in Table 1, in the history of 113 years Nobel Prize awards, without considering the effects of the years which was not award, number of achievement award is 10-14 during each interval time; but there is an obvious change of the winner numbers in every interval time which is shown in table 1 , the most prominent feature is bounded in the 1940s, before the 1940s, the winner number is around 12 in each interval time, but since 1940, the winner number is 20 or above in each interval time, this change indicates that the annual prize winner is single person before the 1940s, while after the 1940s, the annual prize winner number is two or three person.

\section{B. Distribution of prize presentation times, winners and per capita achievement}

Because of the economic depression and the impact of the two world wars, in 1920-1940, there were no Nobel prize award years during the war time, and during the period of 2001-2013, it excess three years for the other periods, for easy comparison, the achievement numbers are used to divided by the winner number and award times and then multiplied by 10 in every period, the results also listed in table 1, the data of chemistry, physics, physiology $\&$ medicine and the three total awards are processed by the same method. Based on the data listed in table 1, the corresponding curve is shown in fig. 3 , where show in fig. 3(A), 3(B), 3(C) and 3(D) are number of awards, winner numbers, amount of award achievement and per capita number of award achievement respectively.

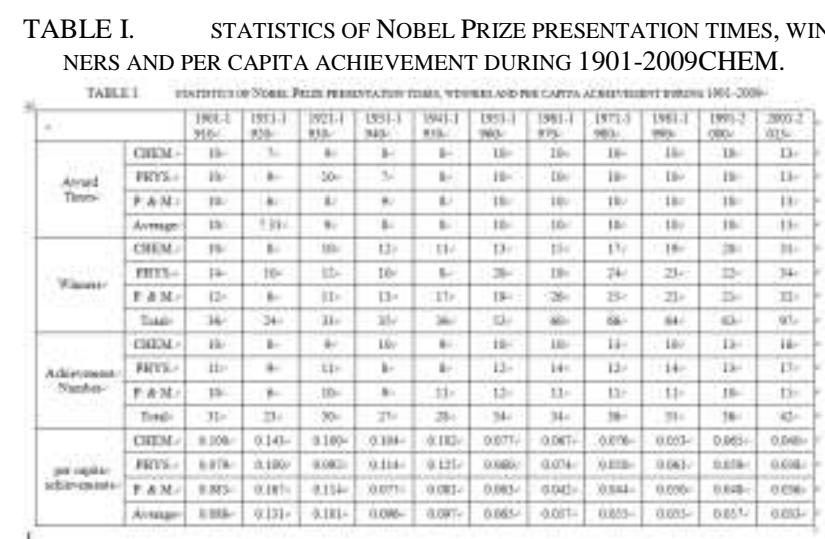

IS ABBREVIATION OF CHEMISTRY; PHYS. IS ABBREVIATION OF PHYSICS, AND P. \& M. IS ABBREVIATION OF PHYSIOLOGY \& MEDICINE

\section{The change of per capita achievement and} Implications for Chinese Universities management

As it is shown in Fig. 3, in the history of the Nobel Prize awards, both of winners and award achievement number in every period are increase with time, but the growth rate shown in fig. 3(B) is higher than the growth rate show in fig. $3(\mathrm{C})$, this difference indicate that the per capita award was significantly decreased in the entire Nobel prize history, this change is shown in 3(D).

The direct reason of this change is the changes in the number of winners, that the annual winner is one person and a small amount is 2 before 1950, but after 1950, the annual winner is 2-3 person, very few situation is one winner. In fact, the deep reasons of this change is the openness of scientific research, with the development of modern transportation and communication, international academic communication and cooperation increasingly convenient, it is possible for researchers in different regions choose a same scientific research problem, and more and more research project are carried out in the form of team, in addition, researchers in different regions may 
well choose the same research project, when the research findings is recognized, improve the probability of 2-3 winners in an award.

All of these indicate the root reason of the amount of per capita achievement award change is the result of international academic exchange, it is the result of worldwide cooperative research, and it is the manifestation of scientific openness.

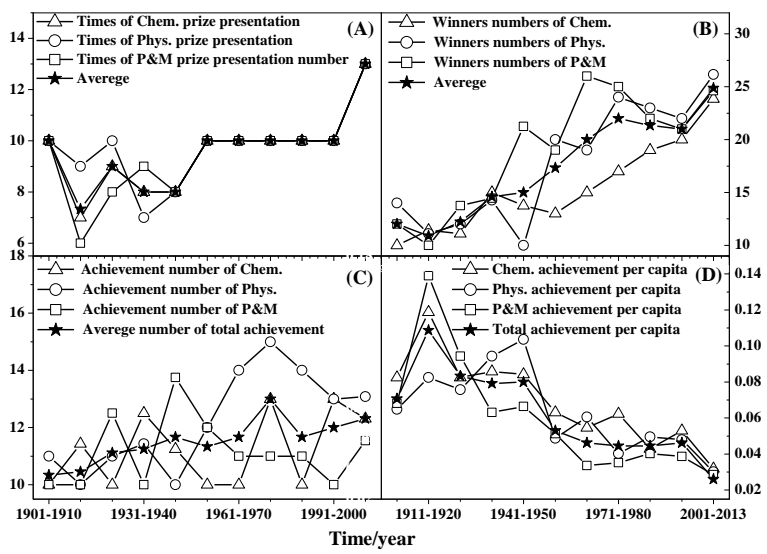

Figure 3. the change of Nobel prize award times, winners, achievement numbers and per capita achievement amount

University is a organization of scientific research, education and social services, it must comply with the openness of scientific research, to carry out and strengthen international exchanges and cooperation, enhance university teachers' international level, especially enhance young teachers' international level; encourage teachers carried out international exchanges and cooperation research; Meanwhile, university is the bridge between school and community, the courses that is helpful for students to develop teamwork curriculum must be set up in university teaching and curriculum.

\section{CONCLUSION}

Nobel Prize is well known as the award for the acknowledged scientific achievements, has recorded the important scientific achievements in the past 113 years, it is also reflected the glorious process of the modern science and technology's development. This paper focuses on the analysis of the phenomenon of Nobel Science Prize; it is mainly focus on the analysis of the winners' nationality and the age distribution as well as per capita achievement amount distribution. From the statistical results, some regular phenomenon and characteristics is summarized. It will provide some reference for higher education when universities make scientific research policies and personnel training plans and management policy.

Nobel Prize is hard-won, rather than by designed. It is a surprise when scientists are in the pursuit of truth research careers. However, as the growth of the seed cannot live without the soil, the scientist work also cannot do without the condition of the talent cultivation. From the nationality and the age distribution Nobel Natural Science Prize winners as well as the per capita variation distribution, we can see easily what makes a big difference on it are the country's economic strength, scientific research institutions, scientists, team spirit and international cooperation and communication. For example: Adequate funding is an effective guarantee for scientific research; the open academic atmosphere provides the space for the scientific research; fair and reasonable mechanism of talent selection and evaluation is an important factor for creativity. From the foregoing, a natural conclusion cans easy drawn that higher school should give the teachers the freedom of opportunities and space, especially young and middle teachers. Only by enforcing the measure into practice, can young and middle teachers' motivation and creativity be played fully, the quality of teaching and research and the management level of colleges and universities be improved effectively, and our higher school, enhance the overall level of learning and competitiveness.

\section{REFERENCES}

[1] Nobel Foundation, http://www.nobelprize.org/alfred_nobel/will/

[2] Jin Bihui, Liu Junwan, "Making Science: Some Characteristics of Research from the Phenomena of the Noble Prize", Science Focus, Vol. 1 (6), June, 2006, PP. 1-9.

[3] Lv Shuqin, Chen Hong, Li Yumin, "Enlightenment of the Nobel Prize", Beijing: Science Publishing House, 2010.7.

[4] Chen Shiwei, "From the perspective of the sociology of science to see 2011 Nobel Prize winner", Decision-Making \& Consultancy Newsletter, Vol. 1, Jan. 2012, PP. 27-28.

[5] Li Wenjie, "A research on the time-lag of performance appraisal of knowledge worker: from Nobel Prize's perspective", Wuhan: Huazhong University of Science and Technology Master Thesis, 2007.

[6] Xu Hexian, "Inheritance law of Nobel Prize in Science in the field of knowledge and talent and inspiration", Science and Technology Management Research, Vol.6, June, 2008, PP. 503-505.

[7] Lin Yongbo, "The Views on Pedagogy about the Non-Nobel Prize Phenomenon in China”, Education Science, Vol.25(6), Dec. 2009, PP. 31-36.

[8] Zhang Yu'e, "Implications of the Nobel Prize for Education", Journal of Suihua Teachers College, Vol. 21 (1), Mar. 2001, PP. 53-56.

[9] Huang Binxian, Meng Jianwei, "Looking Back More Distantly Causes Looking Forward More Distantly, Analysis of Planck's Method and Thought of Scientific History", Journal of Guangxi University for Nationalities (Natural Science Edition), Vol.14 (4), Apr. 2008, PP. 31-35, doi: 10.3969/j.issn.1673-8462.2008.04.009.

[10] Zhao Hongzhou (translation), Yuasa Hikaru (write), "Transfer of scientific activity center", Science and Philosophy, Vol. 1979 (2) PP. 53-57. 